Kansas State University Libraries

New Prairie Press

\title{
MULTI-PARENTAL MATING DESIGN ANALYSIS: MODEL EVALUATION AND APPLICATION IN SPRING WHEAT
}

\author{
M. Kadariya \\ K. D. Glover \\ J. Wu \\ J. L. Gonzalez
}

See next page for additional authors

Follow this and additional works at: https://newprairiepress.org/agstatconference

Part of the Agriculture Commons, and the Applied Statistics Commons

\section{(c) (1) $\Theta($}

This work is licensed under a Creative Commons Attribution-Noncommercial-No Derivative Works 4.0 License.

\section{Recommended Citation}

Kadariya, M.; Glover, K. D.; Wu, J.; and Gonzalez, J. L. (2011). "MULTI-PARENTAL MATING DESIGN ANALYSIS: MODEL EVALUATION AND APPLICATION IN SPRING WHEAT," Conference on Applied Statistics in Agriculture. https://doi.org/10.4148/2475-7772.1050

This is brought to you for free and open access by the Conferences at New Prairie Press. It has been accepted for inclusion in Conference on Applied Statistics in Agriculture by an authorized administrator of New Prairie Press. For more information, please contact cads@k-state.edu. 
Author Information

M. Kadariya, K. D. Glover, J. Wu, and J. L. Gonzalez

This is available at New Prairie Press: https://newprairiepress.org/agstatconference/2011/proceedings/9 


\title{
MULTI-PARENTAL MATING DESIGN ANALYSIS: MODEL EVALUATION AND APPLICATION IN SPRING WHEAT
}

\author{
M. Kadariya, K.D. Glover, J. Wu, and J.L. Gonzalez \\ Plant Science Department, South Dakota State University, \\ Box 2140C, Brookings, SD 57007, USA
}

\begin{abstract}
Conventional quantitative genetics studies have mainly focused on bi-parental mating systems. However, genetic potential of selected individuals within a segregating population may be limited due to only two parents being used for each cross. Multiple-parental mating systems have been proposed that involve three or four diverse parents. This provides a higher potential of combining desirable genes. Due to complexity of the data structure of multi-parental mating systems, analysis of variance (ANOVA) methods are not applicable in analysis. The objective of this study is to validate and apply a mixed linear model approach, minimum norm quadratic unbiased estimation (MINQUE), to analyze a widely used additive-dominance (AD) genetic model. Various simulations were conducted to validate the use of this approach. Twelve different spring wheat genotypes were used to develop populations in the study. Phenotypic data containing parents and their $\mathrm{F}_{2}$ (second filial generation) on preharvest sprouting (PHS) resistance in spring wheat (Triticum aestivum L.) developed by multi-parental crosses were used as a demonstration. The simulation study showed that a modified AD model can be used to estimate variance components in an unbiased manner within this complex data structure. Actual data analysis revealed that both additive and dominance effects were responsible for PHS resistance. Several parents associated with desirable additive effects for PHS were identified. In addition, some crosses with desirable heterozygous dominance effects were also identified, which can be used for hybrid development. Results should help breeders to obtain useful genetic information by using the methods suggested in this study.
\end{abstract}

Key words: Preharvest sprouting, minimum norm quadratic unbiased estimation, additive dominance-model.

\section{Introduction}

Wheat (Triticum aestivum L.) is a major food source for millions of people in the world. There are many factors limiting wheat production, and out of these pre-harvest sprouting (PHS) of grain has been a severe problem in many parts of the world including the US. Pre-harvest sprouting is defined as the condition of in-spike germination of physiologically mature seeds during unfavorable harvest conditions. In other words, PHS occurs when harvest time coincides with relatively high humidity in the field due to untimely rainfall (King, 1984; Derera et al., 1976).

Pre-harvest sprouting has resulted in yield loss, as well as degradation of nutritional and processing quality of grain. This will eventually lead to economic losses to farmers and the processing industry. Exposure of grain to wet conditions during the ripening stage triggers a 
sequence of physiological processes such as release of alpha-amylase enzyme. With increased alpha-amylase activity, the grain carbohydrate reserve is hydrolyzed affecting bread wheat quality causing yield loss, reduced test weight, sticky crumb, collapsed loaves, and dark-colored crusts (Derera et al., 1976; Mares et al., 2005). Hagberg falling number test (AACC, 2000) is used to quantify sprout damage, which measure starch degradation due to alpha amylase activity before appearance of any visible sprouting symptoms (Stoy, 1982). Sound, non-sprouted grain contains less alpha-amylase activity, which prolongs the time to degrade gelatinized starch, and results in a higher falling number. In durum wheat (Triticum turgidum L.), PHS can decrease test weight, increase semolina bran specks, cooking losses, poor color, decreased firmness, and reduced spaghetti stickiness values. Thus, PHS limits the production of high quality wheat for export and also for domestic use.

Since PHS can cause significant damage to wheat growers and processors by reducing yield and baking quality, improving PHS resistance is a prioritized breeding objective that breeders have sought for years. Development of PHS-resistant cultivars is likely the most effective way to address the problem. Pre-harvest sprouting resistant cultivars are highly desirable in wheat growing areas where periods of wet weather frequently occur during harvest. Breeding for PHS resistance is challenging however, as it is quantitatively inherited and influenced by many factors including genetic constitution of the line, gene interaction, environmental conditions, and genotype $\times$ environment interactions. Screening and selection on the basis of phenotype is difficult, and DNA markers linked to genes involved in PHS represent a more reliable tool for selecting resistant genotypes (Tan et al., 2006).

Developing desirable PHS resistance lines with competitive yield potential rely on identification of genetic information among various crosses being made. Data analyses on these crosses play an important role. Many quantitative genetic studies are based on bi-parental mating schemes, which include North Carolina I (NCI), North Carolina II (NC II), and diallel mating designs (Comstock and Robinson, 1948, 1952; Griffing, 1956). By using analysis of variance (ANOVA) methods, valuable genetic information, such as genetic variance components and genetic effects, can be obtained and used for crop improvement. Since selection from bi-parental crosses may be limited, three- or four-parental crosses (i.e., multi-parental crosses) have been used to develop populations for selection (Nandarajan \& Gunasekaran, 2005). Unlike bi-parental mating designs, a multi-parental cross can contain more diverse alleles for selection. However, theoretical investigations on multi-parental mating designs are limited due to complex genetic structures and pedigrees. Further theoretical investigation of multi-parental mating designs will be an important addition to current knowledge associated with genetic mating designs.

Mixed linear model approaches have been proposed and can be used for complex model and unbalanced data structure from long time (Hartley and Rao, 1967; Rao 1971, Zhu, 1998). These are matrix and vector based approaches, which offer flexibility in analyzing complex data structures. There are three types of mixed linear model approaches: maximum likelihood (ML), restricted maximum likelihood (REML), and minimum norm quadratic unbiased estimation (MINQUE) (Hartley and Rao, 1967; Rao, 1971; Searle et al., 1992). The MINQUE approach was proposed by Rao (1971) for estimating variance components and to predict effects of 
interest. Both ML and REML process requires iteration procedure and assumption of normally distributed data. MINQUE approach can be applied to different data distribution and does not require iteration process (Rao, 1971).

Among various genetic models proposed (Zhu, 1993; Wu et al., 2010a), the additive-dominance (AD) model is one of the most commonly used genetic models. Our first objective of this study was to develop and validate an AD model for the complex data structure developed from threeand four-parental crosses. Using mixed linear model approaches, we numerically evaluated empirical Type I errors and testing powers for variance components with simulated genetic data. Our second objective was to apply this AD model and approach to an actual data set composed of 12 spring wheat parents and 109 three- or four-parental crosses. Variance components, heritability, and genetic effects for PHS were calculated.

\section{Materials and Methods}

\subsection{Population development and structure}

In order to increase genetic diversity and combine more favorable alleles in line development, the population in our study was developed from three- or four-way crosses of different spring wheat genotypes. Figure 1, provides an example of development of a single family from a threeway cross giving rise to four individual progeny. In total, 12 spring wheat genotypes were used as parents to create 109 multi-parent families which gave rise to $729 \mathrm{~F}_{2}$ individuals. Complete list of families developed in this along with respective parents used in crosses is presented in Appendix 1. These spring wheat genotypes were selected from spring wheat breeding program and had varying level of PHS resistance.

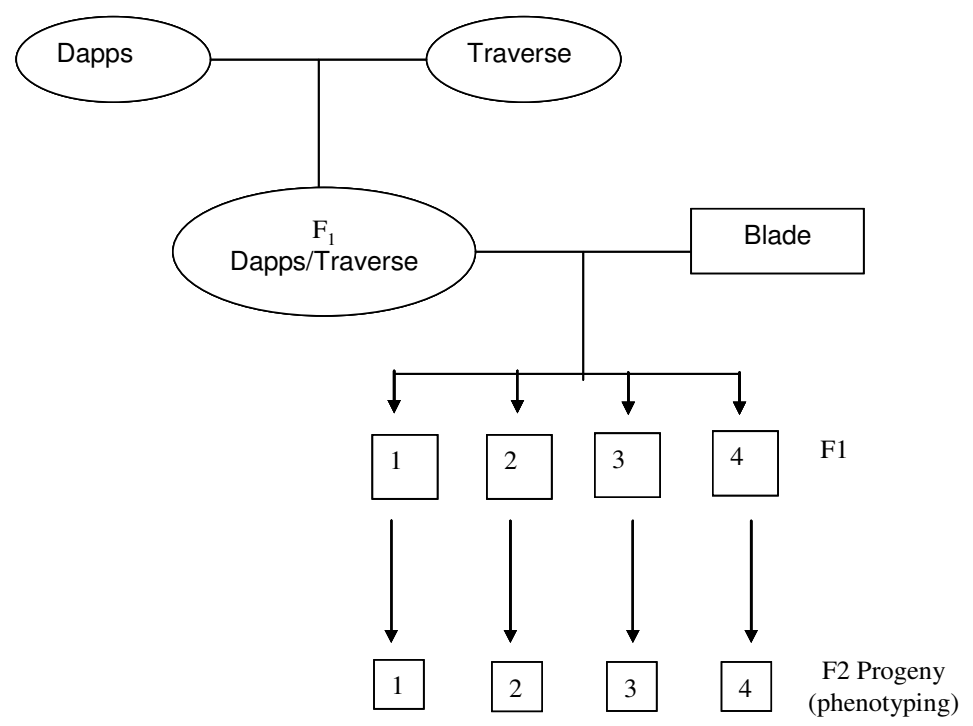

Figure 1. Example of a family 


\subsection{Phenotypic evaluation}

Pre-harvest sprouting resistance test were conducted with $\mathrm{F}_{2}$ progeny from each individual within $\mathrm{F}_{1}$ families. Phenotyping based on a progeny test was performed as a measure of PHS. Intact spikes were hand harvested at physiological maturity (loss of green color from the peduncle and glumes). Harvested spikes were air dried for 3-5 days under ambient temperature and stored in $-20^{\circ} \mathrm{C}$ to preserve dormancy prior to evaluation. Sprouting experiments were carried out in a greenhouse mist chamber developed for this purpose. About 10 spikes from each line were tested visually for sprouting resistance. All spikes were tested by being placed in a rack made of wire mesh. To maximize uniformity of the mist treatment, racks were repositioned daily within chamber (Rasul et al., 2009). Humidity conditions inside the chamber were maintained by applying mist for $60 \mathrm{sec}$ at $60 \mathrm{~min}$ intervals throughout the entire experiment. Spikes were kept inside the chamber for 3-5 days. Spikes of each line were rated based on 0 to 9 scale, where 0 indicated no visible sprouting and 9 indicated extensive visible sprouting over entire spike (McMaster and Derera, 1976). All parents used in developing populations were also tested for PHS resistance and considered checks.

\subsection{Genetic Model and Data analysis}

The AD genetic model and its extensions have been widely used in different studies (Zhu, 1998; Tang et al., 1996; Wu et al., 2010a; Saha et al., 2006; Jenkins, 2006, 2007). Assume that there are no genotype-by-environment interaction effects and there are normal segregations in each cross. Given an AD model, genetic components for parents and crosses (bi-, tri-, and tetraparental crosses) at different generations are different. For generalization and simplicity, we assume that the female is a $\mathrm{F}_{1}$ cross of parents $i$ and $j$ and the male is a $\mathrm{F}_{1}$ cross of parents $k$ and $l$. If these genotypes are evaluated in a field with a randomized complete block (RCB) design, a generalized $A D$ model for the cross of $F_{1(\mathrm{ij})}$ and $\mathrm{F}_{1(\mathrm{kl})}$ in the $\mathrm{r}$ block can be developed based on Cockerham's genetic model (1980):

For $\mathrm{F}_{1}$ :

$$
\begin{aligned}
Y_{i j k l r\left(F_{1}\right)}= & \mu+\frac{1}{2} A_{i}+\frac{1}{2} A_{j}+\frac{1}{2} A_{k}+\frac{1}{2} A_{l}+\frac{1}{4} D_{i k}+\frac{1}{4} D_{j k}+\frac{1}{4} D_{i l}+\frac{1}{4} D_{j l} \\
& +B_{r}+e_{i j k l r}\left(F_{1}\right)
\end{aligned}
$$

For $\mathrm{F}_{2}$ :

$$
\begin{aligned}
Y_{i j k l r\left(F_{2}\right)=} & \mu+\frac{1}{2} A_{i}+\frac{1}{2} A_{j}+\frac{1}{2} A_{k}+\frac{1}{2} A_{l}+\frac{1}{8} D_{i i}+\frac{1}{8} D_{j j}+\frac{1}{8} D_{k k}+\frac{1}{8} D_{l l} \\
& +\frac{1}{8} D_{i k}+\frac{1}{8} D_{j k}+\frac{1}{8} D_{i l}+\frac{1}{8} D_{j l}+B_{r}+e_{i j k l r\left(F_{2}\right)}
\end{aligned}
$$

Where $\mu$ is the population mean; $A_{i}, A_{j}, A_{k}$ or $A_{l}$ is the additive effect; $\left(D_{i i}, D_{j j}, D_{k k}, D_{l l}, D_{i k}, D_{j k}, D_{i l}\right.$ or $\left.D_{j l}\right)$ is the dominance effect; $B_{r}$ is the block effect. The last term is the random error. It is reasonable to treat additive and dominance effects as random because parents were chosen from a large population. 
It must be pointed out that these two equations can be converted to different mating designs. For example, if $\mathrm{i}=\mathrm{j}=\mathrm{k}=1$, the AD model in equations (1) and (2) becomes an AD model for parent. If $\mathrm{i}=\mathrm{j}$ and $\mathrm{k}=1$, the above equations are for a bi-parental cross. If $\mathrm{i}=\mathrm{j}$ and $\mathrm{k} \neq 1$ or $\mathrm{i} \neq \mathrm{j}$ and $\mathrm{k}=1$, these two equation are for a tri-parental cross. If $i \neq j$ and $k \neq 1$, then these equations are for a tetraparental cross. These two equations are more generalized than those for bi-parental crosses reported previously. In addition, if no block effect is included in the model, then this effect $B_{r}$ can be deleted from these two equations.

Analysis of variance methods are unable to estimate variance components and genetic effects for the above two equations which include complex genetic structures. Thus, we applied a mixed linear model approach, minimum norm quadratic unbiased estimation (MINQUE), which has been extensively used in various studies (Zhu, 1989, 1994; Zhu and Weir, 1994; Wu et al., 2006a, b, 2010a,b), to estimate variance components. In order to apply MINQUE approach, the above two equations can be expressed in terms of vectors and matrices as follows:

$y=1 \mu+U_{A} e_{A}+U_{D} e_{D}+U_{E} e_{B}+e_{e}$

Where, $\mathbf{y}$ is an observation vector with dimension $n \times 1$, known; $\mu$ is the population mean as defined as above;

1 is the vector with all elements 1 ;

$e_{A}$ is the vector for additive effects, $e_{A} \sim \operatorname{MVN}\left(0, \sigma_{A}^{2} \mathrm{I}\right)$;

$\boldsymbol{U}_{\boldsymbol{A}}$ is the incidence matrix for additive effects;

$e_{D}$ is the vector for dominance effects, $e_{D} \sim \operatorname{MVN}\left(0, \sigma_{D}^{2} \mathrm{I}\right)$;

$\boldsymbol{U}_{\boldsymbol{D}}$ is the incidence matrix for dominance effects;

$e_{B}$ is the vector for block effects, $e_{B} \sim M V N\left(0, \sigma_{B}^{2} \mathrm{I}\right)$;

$\boldsymbol{U}_{\boldsymbol{B}}$ is the incidence matrix for block effects;

$e_{e}$ is the vector for random errors, $e_{e} \sim M V N\left(0, \sigma_{e}^{2} \mathrm{I}\right)$.

Variance components in the above AD model can be estimated by solving the following MINQUE normal equations for $\mathrm{u}, \mathrm{v}=1,2, \ldots, 4$ if block effects are included:

$$
\left[\operatorname{tr}\left(U_{u}^{T} Q_{\alpha} U_{v}^{T} U_{v} Q_{\alpha} U_{u}\right)\right]\left[\sigma_{u}^{2}\right]=\left[y^{T} Q_{\alpha} U_{u} U_{u}^{T} Q_{\alpha} y\right]
$$

where the trace $t r$ is the sum of diagonals of a matrix and

$$
Q_{\alpha}=V_{\alpha}^{-1}-V_{\alpha}^{-1} X\left(X^{T} V_{\alpha}^{-1} X\right)^{-1} X^{T} V_{\alpha}^{-1}
$$

Where $V_{\alpha}=\sum_{u=1}^{4} \alpha_{u} U_{u} U_{u}^{T}$ and $V_{\alpha}^{-1}$ is the inverse matrix of $V_{\alpha}$ with prior values $\alpha_{u}$ in place of $\sigma_{u}^{2}$ in $V_{\alpha}$. Since different prior values yield similar variance component estimation (Zhu, 1989), we set $\alpha_{u}=1$. 
In this study, we primarily focused on spring wheat data sets which simply follow complete randomized design (CRD), so there were no block effects and block effects were deleted from the model accordingly. Thus, only three components were included. The first section of this study was that of genetic model evaluation, as data set was complicated with either 3 or 4 parents. Simulation study was conducted to evaluate appropriateness of using mentioned genetic model for data analysis. Bias, Type I error, testing power and mean square error (MSE) (Wu et al., 2006a, 2010b) were calculated from simulation procedure based on 200 simulations. In the first case, all variance components were set to zero except random error. This case evaluated Type I error for all variance components except random error. In the second case, all variance components, including random error, were set to 20 . This was done to determine testing powers for different variance components at different probability levels. The jackknife procedure was applied for statistical tests by randomly removing $10 \%$ of observations each time and repeated 20 times (Wu et al., 2010b).

The second section of this study was the application of this genetic model to an actual spring wheat data set. Phenotypic data from $\mathrm{F}_{2}$ progeny from families and parents were analyzed for genetic model evaluation. In addition to variance component estimation, genetic effects for additive effects and dominance effects were predicted by the adjusted unbiased prediction approach (Zhu, 1993). All genetic model evaluation and actual data analysis were conducted by a computer program GenMod (Wu et al., 2010a). Details about this computer program and its use have been described in the paper from previous proceedings of this conference (Wu et al., 2010a).

\section{Results and Discussion}

\subsection{Simulation study}

The simulation study was important to evaluate appropriateness of using this model with the data structure discussed. Simulation results from two different specific cases are presented in Tables 1 and 2. Results showed that each variance component was estimated in an unbiased manner (Table 1). Type I error for both additive and dominance variance were 0.05 and 0.04 respectively.

Table 1. Estimated Type I error for estimating Variance Component for AD model

\begin{tabular}{lllll}
\hline & Pre-set value & Bias & Type I error & MSE \\
\hline $\mathrm{V}_{\mathrm{A}}$ & 0 & 0.00 & 0.050 & 0.816 \\
$\mathrm{~V}_{\mathrm{D}}$ & 0 & 0.114 & 0.040 & 0.675 \\
$\mathrm{~V}_{\mathrm{e}}$ & 20 & 0.037 & - & 0.013 \\
\hline
\end{tabular}

The testing power of both additive and dominance effects were desirable (Table 2). Thus simulated results indicated that using the modified AD genetic model gives an unbiased estimation of variance components with desirable biases, type I error, and testing power. 
Table 2. Estimated Testing Power for estimating Variance Component for AD Model

\begin{tabular}{lllll}
\hline & Pre-set value & Bias & Power & MSE \\
\hline $\mathrm{V}_{\mathrm{A}}$ & 20 & -0.617 & 1.000 & 0.816 \\
$\mathrm{~V}_{\mathrm{D}}$ & 20 & 0.614 & 0.98 & 0.675 \\
$\mathrm{~V}_{\mathrm{e}}$ & 20 & 0.081 & 1.000 & 0.013 \\
\hline
\end{tabular}

\subsection{Actual data analysis}

\subsubsection{Phenotypic means for parents and $F_{2}$ progeny}

In this study, only the PHS trait is discussed among parents and $\mathrm{F}_{2}$ populations. Preharvest sprouting resistance scores of individual plant of parent ranged from 2 to 9 explaining the range of resistance. Mean PHS score of all parents is about 6.798. Mean PHS scores of $F_{2}$ progeny within $\mathrm{F}_{1}$ families range from 4.96 to 7.38 slightly lower than overall parent's score (Table 3 ). However, each $F_{2}$ individual's PHS score within $F_{1}$ families range from 1 to 9, explaining range of resistance level present in populations.

Table 3. Mean, minimum, and maximum PHS score for parents and $\mathrm{F}_{1}$ families

\begin{tabular}{lll}
\hline Parent & & PHS score \\
& Mean & 6.798 \\
& Min & 2.000 \\
F $_{1}$ families & Max & 9.000 \\
& Mean & 6.286 \\
& Min & 4.960 \\
& Max & 7.380 \\
\hline
\end{tabular}

Lists of parents used in the developing populations along with their average PHS scores are listed in Table 4. Among the 12 parents used in this study, 'Dapps' had the lowest PHS score and was most resistant whereas 'Ingot', with highest score was the most susceptible parent. Most of the parents used in the study are susceptible to PHS, whereas some genotypes such as 'ACSnowbird', 'Argent', 'Blade', and 'Grandin' appear moderately susceptible. 
Table 4. Parental means for PHS score

\begin{tabular}{ll}
\hline Parents & Average PHS score \\
\hline AC-SNOWBIRD & 6.008 \\
ARGENT & 6.566 \\
BLADE & 6.425 \\
DAPPS & 5.150 \\
GRANDIN & 6.126 \\
GRANGER & 7.13 \\
HAT-TRICK & 7.35 \\
INGOT & 7.96 \\
LOLO & 7.103 \\
LOSCHA & 7.031 \\
TRAVERSE & 7.042 \\
ULEN & 7.304 \\
\hline
\end{tabular}

\subsubsection{Variance Components}

Explained AD model was used in actual data analysis of this study. Different variance components that make up genetic effects were calculated and summarized as Table 5. Both additive and dominance variance were significant for PHS. This revealed that both variance components were responsible for PHS resistance. Estimated variance components expressed as proportions of total phenotypic variance are summarized in Table 6 .

Table 5. Estimation of Variance Components

\begin{tabular}{lll}
\hline Parameter & Estimate & SE \\
\hline Additive variance $\left(\mathrm{V}_{\mathrm{A}}\right)$ & $0.549^{* * * * * *}$ & 0.036 \\
Dominance variance $\left(\mathrm{V}_{\mathrm{D}}\right)$ & $0.442^{* * *}$ & 0.095 \\
Residuals $\left(\mathrm{V}_{\mathrm{E}}\right)$ & $0.746^{* * * *}$ & 0.018 \\
Phenotypic variance $\left(\mathrm{V}_{\mathrm{P}}\right)$ & $1.738^{* * * *}$ & 0.084 \\
& & \\
\hline$* *=0.01, * * * *=0.0001$ significance level &
\end{tabular}

Heritability estimates are useful in formulating breeding plans to achieve the most progress from selection. Heritability can be defined in several ways, but stated simply it describes how much a character is transferred to offspring from parents. Both broad- and narrow-sense heritabilities were calculated. Broad-sense heritability (ratio of both additive and dominance to phenotypic variance) was 0.57 and narrow-sense heritability (ratio of additive to phenotypic variance) was 0.315 (Table 4). Higher narrow-sense heritability allows for greater progress to be made through 
early-generation trait selection and few tests are generally required. However in this case, where narrow-sense heritability was not high, selection in later generations using tests carried out in space and time is suggested to most effectively improve PHS resistance.

Table 6. Estimated Proportion of Variance Component for AD Model using $\mathrm{F}_{2}$ and Parent's PHS Trait

\begin{tabular}{lll}
\hline Parameter & Estimate & SE \\
\hline $\mathrm{V}_{\mathrm{A}} / \mathrm{V}_{\mathrm{P}}$ & $0.315^{* * * *}$ & 0.022 \\
$\mathrm{~V}_{\mathrm{D}} / \mathrm{V}_{\mathrm{P}}$ & $0.254 * * *$ & 0.041 \\
\hline$* * *=0.001, * * * *=0.0001$ significance level &
\end{tabular}

\subsubsection{Additive effects}

Additive effects which are equivalent to general combining ability in an AD model, is important in line development. Table 7 summarizes additive effects for each spring wheat parent used in this study. Genotypes such as 'Dapps', 'AC-Snowbird' and 'Loscha' had significant negative additive effects, whereas 'Ingot', 'Hat-Trick', 'Granger' and 'Lolo' had significant positive effects for PHS resistance. In order to increase PHS resistance, lower phenotypic values are required. Negative additive effects will increase resistance and positive additive effects will decrease resistance. Parents with significant negative additive effects are good general combiners for increasing resistance. These genotypes can be considered while making crosses to improve resistance against PHS. Parents with significant positive effects will more likely increase susceptibility and should be avoided as much as possible.

Table 7. Predicted Additive Effects for PHS Resistance

\begin{tabular}{lll}
\hline Parents & Estimate & SE \\
\hline DAPPS & $-0.718^{* * * *}$ & 0.051 \\
AC-SNOWBIRD & $-0.796^{* * *}$ & 0.044 \\
LOSCHA & $-0.639^{* * *}$ & 0.052 \\
GRANDIN & -0.065 & 0.036 \\
ULEN & 0.0003 & 0.033 \\
ARGENT & -0.090 & 0.031 \\
INGOT & $0.775^{* * *}$ & 0.038 \\
HAT-TRICK & $0.646^{* * *}$ & 0.000 \\
GRANGER & $0.583^{* * *}$ & 0.000 \\
LOLO & $0.256^{* * *}$ & 0.001 \\
\hline
\end{tabular}

$* * *=0.001$ significance level 


\subsubsection{Dominance effects}

Two types of dominance effects, homozygous (Table 8) and heterozygous dominance effects (Table 9) were predicted. Homozygous dominant effects measure the degree of inbreeding depression following hybrid selfing. Negative homozygous dominance for parents results in greater amount of inbreeding depression in progeny, if the parents are used in cross, following selfing. Both effects are useful in the case where breeders are interested in hybrid development and utilization.

Table 8. Predicted homozygous dominant effect for PHS resistance

\begin{tabular}{lll}
\hline Parent & Estimate & SE \\
\hline DAPPS & $0.567^{*}$ & 0.138 \\
AC-SNOWBIRD & $0.866^{* * * *}$ & 0.125 \\
LOSCHA & $1.496^{* * * *}$ & 0.216 \\
GRANDIN & $-0.779^{* *}$ & 0.152 \\
ULEN & $2.004^{* * * *}$ & 0.270 \\
ARGENT & -0.176 & 0.119 \\
INGOT & -0.116 & 0.127 \\
HAT-TRICK & $-0.526^{* *}$ & 0.112 \\
BLADE & -0.249 & 0.104 \\
GRANGER & -0.522 & 0.188 \\
TRAVERSE & $0.435^{*}$ & 0.121 \\
LOLO & 0.052 & 0.111 \\
\hline$*=0.05 * *=0.01 * * * *=0.0001$ significance level
\end{tabular}

Heterozygous dominant effects are related to specific combining ability for the pair of parents in a cross. Significant heterozygous dominant effect is useful for hybrid development. In this study, crosses that lead to negative estimates of dominance effects can increase resistance against PHS in early generations; where as positive estimates in the crosses might further increase susceptibility. Such information can be used by breeders for capturing heterosis. For example, crosses with negative heterozygous dominance effects such as 'Dapps $\times$ AC-Snowbird', Loscha $\times$ Dapps', 'Dapps $\times$ Ulen' etc from following can be used to capture heterosis for PHS resistance. 
Table 9. Predicted Heterozygous Dominance Effects for PHS Resistance

\begin{tabular}{|c|c|c|}
\hline Parents in cross & Estimate & $\mathbf{S E}$ \\
\hline DAPPS $\times$ AC-SNOWBIRD & $-0.694^{* * * * * *}$ & 0.107 \\
\hline LOSCHA $\times$ DAPPS & $-0.855^{*}$ & 0.255 \\
\hline DAPPS $\times$ GRANDIN & -0.037 & 0.181 \\
\hline DAPPS $\times$ ULEN & $-0.972^{* *}$ & 0.232 \\
\hline DAPPS $\times$ ARGENT & -0.009 & 0.131 \\
\hline DAPPS $\times$ INGOT & -0.545 & 0.179 \\
\hline DAPPS $\times$ HAT-TRICK & 0.007 & 0.150 \\
\hline BLADE $\times$ DAPPS & $-0.767^{*}$ & 0.200 \\
\hline GRANGER × DAPPS & 0.197 & 0.174 \\
\hline DAPPS $\times$ TRAVERSE & $-0.311^{*}$ & 0.077 \\
\hline LOLO $\times$ DAPPS & 0.136 & 0.167 \\
\hline LOSCHA $\times$ AC-SNOWBIRD & -0.684 & 0.266 \\
\hline AC-SNOWBIRD $\times$ GRANDIN & $-0.557^{*}$ & 0.159 \\
\hline ULEN $\times$ AC-SNOWBIRD & -0.479 & 0.194 \\
\hline AC-SNOWBIRD $\times$ ARGENT & -0.027 & 0.095 \\
\hline INGOT × AC-SNOWBIRD & $-0.810^{* *}$ & 0.159 \\
\hline GRANGER $\times$ AC-SNOWBIRD & 0.403 & 0.160 \\
\hline LOSCHA $\times$ GRANDIN & 0.439 & 0.217 \\
\hline $\mathrm{ULEN} \times \mathrm{LOSCHA}$ & $-1.423^{* * * *}$ & 0.223 \\
\hline LOSCHA $\times$ ARGENT & -0.436 & 0.247 \\
\hline LOSCHA × INGOT & -0.228 & 0.142 \\
\hline $\mathrm{LOSCHA} \times \mathrm{BLADE}$ & -0.285 & 0.202 \\
\hline BLADE $\times$ LOSCHA & -0.256 & 0.166 \\
\hline LOSCHA × GRANGER & -0.056 & 0.310 \\
\hline TRAVERSE $\times$ LOSCHA & $0.394^{*}$ & 0.100 \\
\hline LOLO $\times$ LOSCHA & 0.525 & 0.244 \\
\hline ULEN × GRANDIN & 0.188 & 0.076 \\
\hline ARGENT $\times$ GRANDIN & $1.220^{* * * *}$ & 0.182 \\
\hline INGOT × GRANDIN & -0.168 & 0.069 \\
\hline GRANDIN $\times$ HAT-TRICK & 0.114 & 0.102 \\
\hline BLADE $\times$ GRANDIN & $-0.369^{*}$ & 0.110 \\
\hline GRANGER $\times$ GRANDIN & 0.109 & 0.170 \\
\hline TRAVERSE $\times$ GRANDIN & $-0.968^{* * * *}$ & 0.106 \\
\hline ARGENT $\times$ ULEN & 0.079 & 0.148 \\
\hline ULEN × INGOT & -0.218 & 0.206 \\
\hline ULEN $\times$ HAT-TRICK & $1.182^{* * *}$ & 0.216 \\
\hline $\mathrm{ULEN} \times \mathrm{BLADE}$ & $1.027^{*}$ & 0.272 \\
\hline GRANGER $\times$ ULEN & $-0.851^{* * * *}$ & 0.114 \\
\hline ULEN $\times$ TRAVERSE & $-0.995^{* * * *}$ & 0.156 \\
\hline $\mathrm{LOLO} \times \mathrm{ULEN}$ & 0.094 & 0.079 \\
\hline
\end{tabular}




\begin{tabular}{lll}
\hline Parents in cross & Estimate & SE \\
\hline INGOT $\times$ ARGENT & -0.035 & 0.195 \\
ARGENT $\times$ HAT-TRICK & 0.219 & 0.115 \\
BLADE $\times$ ARGENT & -0.018 & 0.134 \\
GRANGER $\times$ ARGENT & $-0.030^{* * *}$ & 0.085 \\
TRAVERSE $\times$ ARGENT & $1.233^{* *}$ & 0.200 \\
LOLO $\times$ ARGENT & $0.861^{*}$ & 0.229 \\
INGOT $\times$ HAT-TRICK & -0.199 & 0.103 \\
BLADE $\times$ INGOT & -0.156 & 0.182 \\
INGOT $\times$ GRANGER & 0.114 & 0.122 \\
TRAVERSE $\times$ INGOT & 0.024 & 0.173 \\
LOLO $\times$ INGOT & 0.067 & 0.114 \\
HAT-TRICK $\times$ BLADE & 0.272 & 0.160 \\
HAT-TRICK $\times$ GRANGER & $0.486^{* * * *}$ & 0.142 \\
TRAVERSE $\times$ HAT-TRICK & $1.155^{* * *}$ & 0.162 \\
LOLO $\times$ HAT-TRICK & 0.443 & 0.138 \\
GRANGER $\times$ BLADE & $0.371^{*}$ & 0.100 \\
TRAVERSE $\times$ BLADE & -0.274 & 0.211 \\
LOLO $\times$ BLADE & 0.355 & 0.210 \\
TRAVERSE $\times$ GRANGER & -0.016 & 0.132 \\
LOLO $\times$ GRANGER & $-1.034^{* *}$ & 0.238 \\
\hline
\end{tabular}

$*=0.05, * *=0.01, * * *=0.001, * * * *=0.0001$ significance level

\section{Summary}

The simulation study showed that a modified AD model can be used to estimate variance components in an unbiased manner within this complex data structure. Application of this model to actual data analysis revealed that both additive and dominance effects were responsible for PHS resistance. Several parents were associated with desirable additive effects for PHS and can be used as good general combiners for improving the trait. In addition, some crosses had desirable heterozygous dominance effects, which can be used for hybrid development. Finally, additional studies can be done using multiple environment case in this study. Modified AD model can be further used in analyzing complex data structure with multiple traits and environments. 


\section{References}

American Association of Cereal Chemists (AACC). 2000. Approved method of AACC, method 56-81B, method 22-07, $10^{\text {th }}$ edn. AACC, St Paul.

Cockerham, C.C. 1980. Random and fixed effects in plant genetics. Theor. Appl. Genet. 56:119131.

Comstock, R.E., and H.F. Robinson, 1948. The components of genetic variance in population of biparental progenies and their use in estimating the average degree of dominance. Biometrics, 4, 254-266.

Comstock, R.E., and H.F. Robinson, 1952. Estimation of the average dominance of genes. Heterosis, pp. 494-516. Ames, Iowa, Iowa State College Press.

Derera, N.F., G.M. Bhatt, and G.J. McMaster.1976. On the problems of PHS of wheat. Euphytica 26:299-308.

Griffing, B. 1956. Concept of general and specific combining ability in relation to diallel crossing systems. Aust. J. Biol. Sci. 9:463-493.

Hartley, H.O., and J.N.K. Rao. 1967. Maximum-likelihood estimation for the mixed analysis of variance model. Biometrika 54:93-108.

Jenkins, J.N., J. Wu, J.C. McCarty, S. Saha, O. Gutierrez, R. Hayes, and D. M. Stelly. 2006. Genetic evaluation for thirteen chromosome substitution lines crossed with five commercial cultivars: I. yield traits. Crop Science 46: 1169-1178.

Jenkins, J.N., J.C. McCarty, J. Wu, S. Saha, O. Guitierrez, R. Hayes, and D. Stelly. 2007. Genetic effects of thirteen Gossypium barbadense L. chromosome substitution lines in topcrosses with upland cotton cultivars: II. Fiber quality traits. Crop Science 47: 561-572.

King, R.W. 1984. Water uptake in relation to preharvest sprouting damage in wheat: grain characteristics. Aust. J. Agri Res. 35:337-345.

Mares, D., K. Mrva, J. Cheong, K. Williams, B. Watson, E. Storlie, M. Sutherland, and Y. Zou. 2005. A QTL located on chromosome 4A associated with dormancy in white- and redgrained wheats of diverse origin. Theor. Appl. Genet. 111:1357-1364.

McMaster, G.J., and N.F. Derera. 1976. Methodology and sample preparation when screening for sprouting damage in cereals. Cereal Res. Commun. 4:251-254.

Nandarajan, N, and M. Gunasekaran. 2005. Quantitative genetics and biometrical techniques in plant breeding. Kalyani Publishers. New Delhi, India.

Rao, C.R. 1971. Estimation of variance and covariance components MINQUE theory. J. Multivar. Anal. 1:257-275.

Rasul, G., D.G. Humphreys, A. Brule-Babel, C.A. McCartney, R.E. Knox and R.M. DePauw and D.J. Somers. 2009. Mapping QTLs for pre-harvest sprouting traits in the spring wheat cross 'RL4452/AC Domain'. Euphytica 168: 363-378. 
Saha S., J.N. Jenkins, J. Wu, J.C. McCarty, R.G. Percy, R.G. Cantrell, and D.M. Stelly. 2006. Effect of chromosome specific introgression in Upland cotton on fiber and agronomic traits. Genetics 172: 1927-1938.

Searle, S.E., G. Casella, and C.E. McCulloch. 1992. Variance components. Wiley, New York, NY.

Stoy, V. 1982. Progress and prospect in sprouting research. In: Kruger, J.E and D. Laberge (eds) $3^{\text {rd }}$ International symposium in pre-harvest sprouting in cereals. Westview Press, Boulder, Colorado, pp 3-7.

Tan, M., P.J. Sharp, M. Lu, and N. Howes. 2006. Genetics of grain dormancy in a white wheat. Aust. J. Agric. Res. 57:1157-1165.

Tang, B., J.N. Jenkins, C.E. Watson, J.C. McCarty, and R.G. Creech. 1996. Evaluation of Genetic variances, heritabilities, and correlations for yield and fiber traits among cotton $\mathrm{F}_{2}$ hybrid populations. Euphytica 91:315-322.

Wu, J., J.C. McCarty, J.N. Jenkins. 2010b. Cotton chromosome substitution lines crossed with cultivars: Genetic model evaluation and seed trait analyses. Theor. App. Genet. 120:14731483.

Wu, J., J.N. Jenkins, and J.C. McCarty. 2008. Testing variance components by two jackknife techniques. Proceedings of Applied Statistics in Agriculture 1-17.

Wu, J., J.N. Jenkins, and J.C. McCarty. 2010a. A generalized approach and computer tool for quantitative genetics study. Proceedings of Applied Statistics in Agriculture 85-106.

Wu, J., J.N. Jenkins, J. C. McCarty, S. Saha, and D. M. Stelly. 2006a. An additive-dominance model to determine chromosomal effects in chromosome substitution lines and other germplasms. Theor. App. Genet. 112:391-399.

Wu, J., J.N. Jenkins, J.C. McCarty, and D. Wu. 2006b Variance component estimation using the ADAA model when genotypes vary across environments. Crop Science 46: 174-179.

Zhu, J. 1989. Estimation of genetic variance components in the general mixed model. Ph.D. Dissertation, North Carolina State University, Raleigh, NC

Zhu, J. 1993. Methods of predicting genotype value and heterosis for offspring of hybrids. (Chinese). Journal of Biomathematics 8(1): 32-44.

Zhu, J. 1994. General genetic models and new analysis methods for quantitative traits. J. Zhejiang Agric. Univ. 20(6):551-559.

Zhu, J. 1998. Analytical methods for genetic models. Press of China Agriculture, Bejing, China.

Zhu, J., and B.S. Weir. 1994. Analysis of cytoplasmic and maternal effects. I. A genetic model for diploid plant seeds and animals. Theor. App. Genet. 89:153-159. 
Appendix 1. List of families along with respective spring wheat gentotypes used in crossing.

\begin{tabular}{|c|c|c|c|c|c|}
\hline Family & Parent 1 & Parent 2 & Parent 3 & Parent 4 & Progeny \\
\hline 1 & Dapps & Ac-snowbird & Loscha & & 4 \\
\hline 2 & Dapps & Ac-snowbird & Grandin & & 14 \\
\hline 3 & Dapps & Ac-snowbird & Ulen & & 5 \\
\hline 4 & Dapps & Ac-snowbird & Dapps & Argent & 3 \\
\hline 5 & Dapps & Ac-snowbird & Ingot & & 3 \\
\hline 6 & Dapps & Argent & Hat-trick & & 6 \\
\hline 7 & Dapps & Argent & Blade & & 1 \\
\hline 8 & Dapps & Argent & Ulen & & 5 \\
\hline 9 & Dapps & Argent & Grandin & & 5 \\
\hline 10 & Dapps & Argent & Argent & & 5 \\
\hline 11 & Dapps & Argent & Dapps & Ulen & 2 \\
\hline 12 & Dapps & Argent & Dapps & Ingot & 2 \\
\hline 13 & Dapps & Blade & Blade & & 12 \\
\hline 14 & Dapps & Blade & Ingot & & 12 \\
\hline 15 & Dapps & Blade & Grandin & & 2 \\
\hline 16 & Dapps & Blade & Granger & & 4 \\
\hline 17 & Dapps & Blade & Loscha & Dapps & 4 \\
\hline 18 & Dapps & Blade & Ulen & & 4 \\
\hline 19 & Dapps & Blade & Dapps & Granger & 10 \\
\hline 20 & Dapps & Blade & Dapps & Hat-Trick & 3 \\
\hline 21 & Dapps & Grandin & Grandin & & 7 \\
\hline 22 & Dapps & Grandin & Ulen & & 4 \\
\hline 23 & Dapps & Grandin & Loscha & & 2 \\
\hline 24 & Dapps & Grandin & Hat-Trick & & 3 \\
\hline 25 & Dapps & Granger & Granger & & 4 \\
\hline 26 & Dapps & Granger & Hat-Trick & & 7 \\
\hline 27 & Dapps & Granger & Ulen & & 7 \\
\hline 28 & Dapps & Granger & Ingot & & 14 \\
\hline 29 & Dapps & Granger & Ac-snowbird & & 8 \\
\hline 30 & Dapps & Granger & Loscha & & 5 \\
\hline 31 & Dapps & Granger & Traverse & & 10 \\
\hline 32 & Dapps & Granger & Blade & & 8 \\
\hline 33 & Dapps & Granger & Grandin & & 8 \\
\hline 34 & Dapps & Granger & Dapps & Hat-Trick & 5 \\
\hline 35 & Dapps & Granger & Argent & & 5 \\
\hline 36 & Dapps & Hat-Trick & Blade & & 7 \\
\hline 37 & Dapps & Hat-Trick & Dapps & Loscha & 9 \\
\hline 38 & Dapps & Hat-Trick & Granger & & 6 \\
\hline 39 & Dapps & Hat-Trick & Ulen & & 4 \\
\hline
\end{tabular}




\begin{tabular}{|c|c|c|c|c|c|}
\hline Family & Parent 1 & Parent 2 & Parent 3 & Parent 4 & Progeny \\
\hline 40 & Dapps & Hat-Trick & Traverse & & 11 \\
\hline 41 & Dapps & Hat-Trick & Ingot & & 9 \\
\hline 42 & Dapps & Hat-Trick & Dapps & LoLo & 6 \\
\hline 43 & Dapps & Hat-Trick & Dapps & Ulen & 6 \\
\hline 44 & Dapps & Ingot & Ulen & & 5 \\
\hline 45 & Dapps & Ingot & Ac-snowbird & & 11 \\
\hline 46 & Dapps & Ingot & Loscha & & 3 \\
\hline 47 & Dapps & Ingot & Ingot & & 13 \\
\hline 48 & Dapps & Ingot & Granger & & 5 \\
\hline 49 & Dapps & Ingot & Argent & & 6 \\
\hline 50 & Dapps & Ingot & Traverse & & 12 \\
\hline 51 & Dapps & Ingot & Dapps & Ulen & 3 \\
\hline 52 & Dapps & Ingot & Grandin & & 9 \\
\hline 53 & Dapps & Ingot & Dapps & Hat-Trick & 11 \\
\hline 54 & Dapps & Ingot & Dapps & Loscha & 7 \\
\hline 55 & Dapps & Ingot & Dapps & Traverse & 4 \\
\hline 56 & Dapps & Ingot & Blade & & 3 \\
\hline 57 & Dapps & LoLo & Ulen & & 8 \\
\hline 58 & Dapps & LoLo & Dapps & Hat-Trick & 8 \\
\hline 59 & Dapps & LoLo & Granger & & 8 \\
\hline 60 & Dapps & LoLo & Loscha & Dapps & 2 \\
\hline 61 & Dapps & LoLo & Ingot & & 3 \\
\hline 62 & Dapps & LoLo & Blade & & 6 \\
\hline 63 & Dapps & LoLo & Traverse & & 7 \\
\hline 64 & Dapps & LoLo & Argent & & 4 \\
\hline 65 & Dapps & LoLo & Traverse & Dapps & 5 \\
\hline 66 & Dapps & LoLo & Dapps & Ingot & 12 \\
\hline 67 & Dapps & LoLo & Loscha & & 3 \\
\hline 68 & Dapps & Loscha & Ingot & & 6 \\
\hline 69 & Dapps & Loscha & Argent & & 10 \\
\hline 70 & Dapps & Loscha & Granger & & 10 \\
\hline 71 & Dapps & Loscha & Grandin & & 19 \\
\hline 72 & Dapps & Loscha & Traverse & & 11 \\
\hline 73 & Dapps & Loscha & Hat-Trick & & 7 \\
\hline 74 & Dapps & Loscha & Ac-snowbird & & 7 \\
\hline 75 & Dapps & Loscha & Dapps & Ulen & 7 \\
\hline 76 & Dapps & Loscha & Dapps & Ingot & 15 \\
\hline 77 & Dapps & Loscha & Loscha & & 6 \\
\hline 78 & Dapps & Loscha & Dapps & Granger & 7 \\
\hline 79 & Dapps & Loscha & Ulen & & 3 \\
\hline 80 & Dapps & Traverse & Ulen & & 10 \\
\hline
\end{tabular}




\begin{tabular}{|c|c|c|c|c|c|}
\hline Family & Parent 1 & Parent 2 & Parent 3 & Parent 4 & Progeny \\
\hline 81 & Dapps & Traverse & Grandin & & 8 \\
\hline 82 & Dapps & Traverse & Ingot & & 12 \\
\hline 83 & Dapps & Traverse & Granger & & 9 \\
\hline 84 & Dapps & Traverse & Hat-Trick & & 12 \\
\hline 85 & Dapps & Traverse & Blade & & 4 \\
\hline 86 & Dapps & Traverse & Traverse & & 5 \\
\hline 87 & Dapps & Traverse & Loscha & Dapps & 5 \\
\hline 88 & Dapps & Traverse & Argent & & 6 \\
\hline 89 & Dapps & Traverse & Dapps & Ulen & 6 \\
\hline 90 & Dapps & Traverse & Dapps & Loscha & 2 \\
\hline 91 & Dapps & Traverse & Dapps & Hat-Trick & 4 \\
\hline 92 & Dapps & Traverse & Dapps & Blade & 2 \\
\hline 93 & Dapps & Ulen & Ingot & & 6 \\
\hline 94 & Dapps & Ulen & Traverse & & 10 \\
\hline 95 & Dapps & Ulen & Ulen & & 6 \\
\hline 96 & Dapps & Ulen & Hat-Trick & & 6 \\
\hline 97 & Dapps & Ulen & Ac-snowbird & & 8 \\
\hline 98 & Dapps & Ulen & Blade & & 10 \\
\hline 99 & Dapps & Ulen & Grandin & & 4 \\
\hline 100 & Dapps & Ulen & Dapps & Blade & 7 \\
\hline 101 & Dapps & Ulen & Dapps & Hat-Trick & 10 \\
\hline 102 & Dapps & Ulen & Dapps & Granger & 2 \\
\hline 103 & Dapps & Ulen & Loscha & & 7 \\
\hline 104 & Dapps & Ulen & Dapps & Loscha & 5 \\
\hline 105 & Dapps & Ulen & Dapps & Ingot & 7 \\
\hline 106 & Dapps & Blade & Argent & & 5 \\
\hline 107 & Dapps & Granger & Dapps & Ingot & 4 \\
\hline 108 & Dapps & Granger & Dapps & Ulen & 8 \\
\hline 109 & Dapps & Loscha & Dapps & Hat-Trick & 3 \\
\hline
\end{tabular}

